With increasing age there is the usual increase of cases against the rule: the only keratoconus had $8 \mathrm{D}$. of astigmatism with the rule. These are two facts commonly quoted in support of the contention that physiological astigmatism is due to lid pressure on the globe.

The only factor which I can suggest as responsible for this inversion of the rule in Indians is trachoma, which is found in a majority of the soldiers seen in this part of India, and often in severe form. This is offered solely as a suggested explanation: I find no reference to the condition in the text-books available, and have no access to the literature.

I wish to thank the Commanding Officer, British Military Hospital, Delhi for leave to publish this note.

Yours faithfully,

R. A. D. CRAWFORD.

Major, R.A.M.C., Ophthalmic Specialist

Agram, Bangalore,

INDIA COMMAND.

\title{
THE "NORMAL" IN THE SYNOPTOPHORE
}

To the Editors of THE BRITISH JOURNAL OF OPHTHALMOLCGY.

DEAR SIRS,-Referring to the paper by M. M. Lewis in your December issue and to $\mathrm{N}$. Cridland's comments in the February issue, I would suggest that the latter's statement that ". . . . I do not think that there is, on the face of it, reason to suppose that the synoptophore and the Maddox rod measure different qualities of heterophoria" should not pass without comment.

I am not clear as to the meaning of the term "qualities of heterophoria" but, with regard to the degree of heterophoria that will be revealed, surely when the two eyes are dissociated so that the visual mechanism finds itself in an unusual state of balance, or imbalance, to deal with which it has no safe guide from its normal experience, it is to be expected that the position taken up by the eyes will fluctuate round about a mean position which may be definitely affected by the kind of apparatus that has been used to secure dissociation. This is to be expected especially when testing at near, when the whole mechanism is in a dynamic state and by suspending: fusion we have eliminated the incentive for the governing innervation of the complex group of innervations that are in operation. I think that many practitioners will agree that this expectation is borne out in practice; for the results obtained, 
especially in near testing, with the Maddox rod method do not in general agree with those obtained with the synoptophore.

Yours faithfully,

H. H. EMSLEY.

ALLIED INSTRUMENT MANUFACTURERS LTD.

20-24, PARKWAY, N.W.1.

March 13, 1947.

\section{REMOVAL OF THE WRONG EYE}

To the Editors of THE BRITISH JOURNAL OF OPHTHALMOLOGY.

DEAR SIRS, - I am grateful to Dr. Ascher for his letter on my paper on "Removal of the wrong eye." At the same time I do not follow his inference that the paper suggests that a case of this kind occurred in Elschnig's clinic either before or after 1908. Dr. Ascher's remarks about the meaning of "Soll" are, of course, correct, but seem to me to be irrelevant. I made no attempt at a literal translation as I thought that clumsy English would result and the free rendering I gave of the sentence in question conveys no implication of the kind Dr. Ascher indicates.

I have no information that such a case ever occurred in Elschnig's clinic but $I$ am assured that Elschnig used to impress the dangers of this accident on his students, which suggests that he had heard of at least one case. The significance of his foot-note is clear: it means that between writing his text and correcting the proofsotherwise why a foot-note?-he had learned of another case. I was careful to write "within his knowledge." The case may have occurred anywhere, possibly outside Austria altogether.

Cutting the eyelashes is only another method of marking the eye, though perhaps a better one than the use of adhesive plaster. The important point is that, for one reason or another, methods of marking the eye have proved unreliable.

I have for many years given up cutting the lashes in eye operations except sometimes a few at the lateral and medial ends of the upper lid. I doubt whether any advantage is gained by cutting even these.

Yours faithfully,

H. M. TRAQUAIR.

16, MANOR PLACE,

EDINBURGH, 3.

April 10, 1947. 